\title{
CORRIGENDUM
}

\section{Ultrafast fibre lasers}

Martin E. Fermann \& Ingmar Hartl

Nature Photon. 7, 868-874 (2013); published online 20 October 2013; corrected after print 28 October 2013.

In the version of this Review Article originally published online and in print, the label for the horizontal axis in Fig. 3 should read "Wavelength $(\mu \mathrm{m})$ " and not "Wavelength (nm)". This has now been corrected in both the HTML and PDF versions of the Review Article. 